\title{
Effort-Related Decision-Making and its Underlying Processes during Childhood
}

Running Title: Effort-Related Decision-Making during Childhood

Authors: Keertana Ganesan, and Nikolaus Steinbeis

Authors' institutional affiliations: Division of Psychology and Language Sciences, University College London, London, United Kingdom

Corresponding Author: Keertana Ganesan, Division of Psychology and Language

Sciences, University College London, 26 Bedford Way, London,

WC1H 0AP; keertana.ganesan.18@ucl.ac.uk

Conflict of Interest Statement. The authors have no conflict of interests to declare.

Acknowledgements. This research is funded by an ERC Starting Grant and a JacobsFoundation Early Career Research Fellowship awarded to Nikolaus Steinbeis. We would like to thank $\mathrm{Dr}$ Abigail Thompson, Claire Smid, Somya lqbal, Joshua Spowage, Harriet Phillips, Sebastijan Veselic and Ellina Guijt for helping with data collection.

Paper has been accepted by Developmental Psychology.

(C) 2021, American Psychological Association. This paper is not the copy of record and may not exactly replicate the final, authoritative version of the article. Please do not copy or cite without authors' permission. The final article will be available, upon publication, via its DOI: $10.1037 / \operatorname{dev0001228}$ 


\section{EFFORT-RELATED DECISION-MAKING DURING CHILDHOOD}

Humans tend to avoid cognitive effort. Whereas evidence of this abounds in adults, little is known about its emergence and development in childhood. The few existing studies in children use different experimental paradigms and report contradictory developmental patterns. We examined effort-related decision-making in a sample of 79 5-11-year-olds using a parametric induction of cognitive effort and three paradigms that each involved decision-making between low- and high-effort options but varied in how explicit effort was made. This included a demand avoidance and an effort discounting paradigm. We also probed cognitive processes linked to effort-related decisions, including task performance, metacognitive accuracy, effort perception and mental demand. We found that children of all ages were sensitive to parametric modulations of cognitive effort as indicated by self-report. In terms of effort-related decisionmaking we found that overall children demonstrated no implicit behavioural preference for low effort tasks, that older children stated a preference for low effort tasks and that all children discounted effort. Further, implicit preference in the demand avoidance paradigm was linked to children's metacognitive insight into how well they could perform effortful tasks. These findings strongly suggest that while children are clearly sensitive to manipulations of cognitive effort, whether and when they use this information to guide their decisions to engage in effortful tasks depends strongly on the extent to which effortful features are made salient to them.

Key words: Effort-related decision making, demand avoidance, effort discounting, metacognition, mental demand 


\section{EFFORT-RELATED DECISION-MAKING DURING CHILDHOOD}

Humans tend to avoid effort, be it physical or mental (Bonnelle, Veromann, Heyes, Sterzo, Manohar, \& Husain, 2015; Dunn, Lutes, \& Risko, 2016; Kool, McGuire, Rosen, \& Botvinick, 2010; Niebaum, Chevalier, Guild, \& Munakata, 2018). Effort is aversive (Dreisbach, \& Fischer, 2015; Saunders, Lin, Milyavskaya, \& Inzlicht, 2017) and all else being equal, individuals prefer tasks that make fewer demands (Kool et al., 2010; Niebaum et al., 2018). Prominent theories argue that the aversion induced by effort acts as a value signal forcing individuals to prioritise their goals (Kurzban, 2016; Shenhav, Botvinick, \& Cohen, 2013; Shenhav, Cohen, \& Botvinick, 2016). It has been shown that willingness to expend effort can account for performance on demanding tasks (Krebs, Boehler, \& Woldorff, 2010; Kurzban, Duckworth, Kable, \& Myers, 2013; Umemoto \& Holroyd, 2015), which in turn can explain group differences in task performance typically attributed to differences in ability (Foussias et al., 2015; Salamone, Yohn, Lopez-Cruz, San Miguel, \& Correa, 2016; Westbrook et al., 2020). Critically, developmental differences on cognitively challenging tasks can at least partly be explained by motivation (Carlson, 2005; Chevalier, Huber, Wiebe, \& Espy, 2013; Davidson, Amso, Anderson, \& Diamond, 2006). A better understanding of the nature of developmental change in cognitive abilities therefore requires a thorough assessment of the processes underlying engagement in effortful tasks.

How the experience of effort affects task engagement has been studied using different methods varying in the degree to which effort is made explicit, namely demand avoidance and effort discounting paradigms. In demand avoidance paradigms subjects choose between task options that differ only in effort level, a feature that is not made explicit. These tasks require monitoring of task demands and coordinating behaviour accordingly (i.e. choosing low effort tasks; Dunn et al., 2016; Kool et al., 2010; Niebaum et al., 2018). In effort discounting paradigms on the other hand subjects choose between options that differ explicitly in how much effort is to be expended and how much reward is to be gained. This allows estimating the costs associated with effort (Chong, Apps, Giehl, Sillence, Grima, \& Husain, 2017; Massar, 


\section{EFFORT-RELATED DECISION-MAKING DURING CHILDHOOD}

Libedinsky, Weiyan, Huettel, \& Chee, 2015; Westbrook, Kester, \& Braver, 2013). Adults have been shown to avoid cognitively demanding tasks (Dunn et al., 2016; Kool et al., 2010) and devalue effort (Chong et al., 2017; Massar et al., 2015; Westbrook et al., 2013). It is believed that the same underlying computation may subserve both implicit and explicit effort-related decision-making (Botvinick, Huffstetler, \& McGuire, 2009; McGuire \& Botvinick, 2010), but whether these constructs correlate has yet to be tested.

Infants and pre-schoolers readily compute costs associated with actions, (Liu, Ullmann, Tenenbaum, \& Spelke, 2017; Leonard, Lee, \& Schulz, 2017) and are sensitive to others' effort and energy expenditure (Leonard, Garcia, \& Schulz, 2019) spawning developmental theories on naïve utility understanding (Jara-Ettinger, Gweon, Schulz \& Tenenbaum, 2016) and persistence (Lucca \& Sommerville, 2018; Lucca, Horton \& Sommerville, 2020). How such computations inform decisions on whether to engage in effortful tasks and how this changes over the course of child development remains unclear however. Using an implicit demand avoidance paradigm, Niebaum et al. (2018) found that adults and 11-12-year-old children demonstrated a preference for low effort tasks, whereas 6-7-year-old children did not. All age groups performed comparably as indicated by reaction times and accuracy and thus presumably found tasks equally challenging. This suggests that younger children were not yet able to use task-demand signals to coordinate behaviour away from effort. By contrast, a study on the development of explicit effort discounting using an n-back task in 6-12-year-olds found that children devalued effort equally irrespective of age (Chevalier, 2018). One interpretation of these discrepant findings is that children become better at using implicit task demand signals to avoid effort, a requirement that is lessened in the context of explicit discounting paradigms. However, given that at the very core of effort-related decision-making lies a sensitivity to task demands an alternative interpretation is that the specific tasks represent non-trivial features in study design and that these can influence detection of age-related changes. Further, the lack of developmental differences in explicit devaluation of effort 


\section{EFFORT-RELATED DECISION-MAKING DURING CHILDHOOD}

(Chevalier, 2018) could be due to the particularly salient operationalisation of effort (i.e. nback tasks). To obtain convergent results, we based our measures of implicit and explicit effort-related decision-making on the same experimental paradigm, namely an attentional switch task. Crucially, our task employed a fine-grained parametric manipulation of effort (i.e. six effort levels; Chong et al., 2017; Yantis et al., 2002), which arguably possesses greater sensitivity to detect possible age-related changes that might have previously been masked.

One further question relates to the underlying processes of effort-related decision-making in childhood. As candidate processes, we identify 1) task performance, 2) representation of task performance (i.e. metacognition); and 3) effort perception. Task performance is the most frequently studied in terms of its relation to effort decisions, but findings of an association are mixed (Chong et al., 2017; Chevalier, 2018; Niebaum et al., 2018). One other potential factor that could account for effort-related decisions is the perception of one's performance rather than actual performance. Given the limits of cognitive resources, it is necessary to ensure the exertion of effort is worthwhile, by weighing up its cost against any associated gains (Kurzban et al., 2013; Shenhav et al., 2013, 2016). Such computations are subserved by metacognitive insight into one's performance and this could be a critical factor in deciding to engage in effortful tasks (Dunn \& Risko, 2016). Indeed, younger children have been found to conflate effort exerted with their ability (Nicholls, 1978; Muradoglu \& Cimpian, 2020) and metacognitive abilities have been reported to improve with age (Shin, Bjorklund, \& Beck, 2007; Chevalier \& Blaye, 2016). This could account for potential developmental changes in effort-related decision-making, particularly when these are made in the context of implicit tasks. Finally, how effortful a given task is perceived to be (Robinson \& Morsella, 2014) could also bias an individual's estimation of costs associated with the exertion of effort. While previous research has found that high effort tasks are perceived to be more effortful (Chong et al., 2017; Niebaum et al., 2018), it is unclear how such perception may influence effort-related decisions. 


\section{EFFORT-RELATED DECISION-MAKING DURING CHILDHOOD}

In sum, by using a parametric induction of cognitive effort, the present study examined (i) implicit and explicit forms of effort-related decision-making during childhood; and (ii) how alongside age, effort-related decision-making during childhood is related to individual differences in perceived effort, task performance and metacognitive insight into performance.

\section{Method}

\section{Participants}

Participants were recruited from a school in Greater London, aged between 5.10 - 11.20 years $(M=7.91$ years, $S D=1.57)$, normally developing and predominantly White. Parental consent was obtained beforehand and the study was approved by the UCL research ethics committee (Project title: Neurocognitive mechanisms of inhibitory control training and transfer effects in children; Protocol number: 12271/001). Testing took place at school with children being tested in pairs. Children were tested apart from each other and wore headphones while completing the tasks. They were told beforehand that they could win gifts ranging in size depending on reward collected during the tasks. Data was collected from 117 children. Due to some unforeseen circumstances, complete data was obtained only from 79 participants $(M=8.06$, $S D=1.58)$. There were no age differences between those with complete and those with incomplete data $(t(115)=1.28, p=.202)$. We conducted a power analysis based on effect size estimates from a previous study examining developmental changes in effort-related decisions (Chevalier, 2018) to determine whether the present study has enough power to detect the effects of interest. Chevalier (2018) reported a main effect of effort level on various outcomes with age as an interaction variable. The effect size in this study was 1.57 which is considered very large (Cohen, 1988). With the power to detect this effect at 0.80 and an alpha of 0.05 , the projected sample size to detect such an effect is 48 . Based on this, we consider this study to be sufficiently powered to detect any main effects of attentional switches (i.e. effort levels) and age interactions. 


\section{Procedure}

Participants first completed five rounds of the effort manipulation in the form of an attentional switch task to familiarise them with the task. To examine both implicit and explicit forms of effort-related decisions, we used a demand avoidance paradigm and effort discounting paradigm. The paradigms were administered in the following order: 1. Demand Avoidance: Choice Behaviour; 2. Demand Avoidance: Preference Statement; 3. Metacognition; 4. Effort Experience; 5. Effort Discounting. This order ensured that any findings from the Demand Avoidance and Metacognition paradigms were not confounded by the explicit knowledge of effort differences in each trial or option. Further, the effort experience gave participants the opportunity to experience the different effort levels before making their decisions in the discounting paradigm.

\section{Effort manipulation (Attentional switch task)}

A rapid serial visual presentation (RSVP) or attentional switch task was used where cognitive effort was manipulated by changing the number of attentional switches participants had to make. This allowed for a parametric, fine-grained modulation of effort (Chong et al., 2017; Yantis et al., 2002). We adapted the original task to be more child-friendly (i.e. changing numbers and words to images; Figure 1A). In our task, participants fixated centrally and had to monitor one of two target streams, each presented on either side of the central fixation. Each target stream was surrounded by three distractor streams. Participants had to respond to a target (i.e. a wand) by pressing the spacebar. A total of three targets appeared per trial. At the beginning of each trial, a direction cue appeared for $4 \mathrm{~s}$ to indicate which target stream participants had to attend to. During the trial, switch cues (i.e. an owl) were also presented centrally, indicating participants to switch their attention to the opposite side. The number of switches participants had to make was parametrically modulated (i.e. 1-6 times) and varied on any given trial. Each trial consisted of 40 serial presentations, each presented for $350 \mathrm{~ms}$. 


\section{EFFORT-RELATED DECISION-MAKING DURING CHILDHOOD}

Intervals between switches were pseudorandomised. This task was used throughout as manipulation of cognitive effort the basis of effort-related decisions.

\section{Demand Avoidance Paradigm}

Choice Behaviour. Participants were introduced to two protagonists, an ice and fire witch, each associated with completing either two or six attentional switches (low or high effort; Figure 1B). The associations between witch and effort level were counterbalanced across participants. Importantly, participants were not told of any differences between the witches. Participants first completed 6 rounds of low and high effort trials each. Following this, participants could choose between the two witches over 30 trials. After each choice, they completed a trial of the attentional switch task that was low (2 switches) or high (6 switches) in effort depending on their choice. The measure of interest was the percentage of trials in which participants chose the low-effort option. Choice behaviour from the demand avoidance paradigm reflects an implicit form of effort-based decision.

Before making their choices, we checked comprehension of the paradigm relating to 1) what objects needed to be collected; 2) how the objects can be collected; 3) how participants know which side of the screen to focus on; 4) what participants should do if the switch cue points to the left; 5) what participants should do if the switch cue points to the right; 6) what participants need to do at the beginning of each round; and 7) which keys needed to be pressed to help each witch. Experimenters were trained beforehand on a range of acceptable responses to these questions that exhibited comprehension of the paradigm. If a participant was unable to provide a correct response, the paradigm was explained once more, and the participant was probed again. All participants passed these validation questions.

Preference Statement. After the 30 choices, participants were asked to state which of the two witches they preferred. The preference statement reflects a more explicit form of decision 
making as participants are asked to report a preference (i.e. subtle cuing; Dunn et al., 2016; Kool et al., 2010).

\section{Metacognition Paradigm}

To obtain a measure of metacognitive insight into their task performance, participants performed 8 trials of the attentional switch task, half of which required them to make 2 and the other half 6 attentional switches. After each trial, participants rated on a 6-point scale how well they thought they had done (from 'Very poorly' to 'Very well'). Importantly, differences in the number of switches to be made in each trial were not made explicit to ensure this would not confound rating of performance.

\section{Effort Experience Paradigm}

Participants performed three iterations of the task at each effort level (i.e. 18 trials). After the experience of each effort level, participants were given a child adapted NASA Task Load Index to report perceptions of the task (Laurie-Rose, Curtindale, \& Frey, 2017).

\section{Effort Discounting Paradigm}

Participants were told that they would be making choices between options varying in attentional switches for which they could win rewards (i.e. tokens). They were told that they would be presented with a series of choices between a baseline option (i.e. low effort, low reward) and a variable option (i.e. high effort, high reward; Figure 1C). They were instructed to choose their preferred option and that they would be given a random selection of chosen trials to perform at the end of the experiment. They were told that any tokens earned in this phase would contribute to a gift at the end of the experiment. Participants were presented with a series of 75 binary choices, each with a combination of effort and reward. The baseline 


\section{EFFORT-RELATED DECISION-MAKING DURING CHILDHOOD}

option always entailed performing the lowest effort level (i.e. effort level 1) for the lowest reward (i.e. 1 token). The other option presented alongside varied from performing a 2-6 effort level for 2, 4, 6, 8 or 10 tokens. Effort was depicted by a pie chart with different levels and reward was depicted by gems (Figure 1C). Order of presentation of the variable options was fully counterbalanced and randomized. Effort discounting was administered as the most explicit form of effort-based decision-making with all task features made highly salient (Chong et al., 2017; Massar et al., 2015; Westbrook et al., 2013).

Before making their choices, comprehension questions were administered relating to 1) what each pie level indicates; 2 ) what a pie level of 2 indicates; 3 ) whether participants need to work harder on a game with a pie level of 2 or 4 ; 4) through which games more gems can be earned - pie level 1 or 5; and 5) what participants can do with the gems they earn. Experimenters were trained beforehand on a range of acceptable responses to these questions that exhibited comprehension of the paradigm. If a participant was unable to provide a correct response, the paradigm was re-explained and the participant was quizzed again. All of our participants passed these validation questions and were included for analysis.

\section{Statistical Analysis}

To examine age-related differences, Pearson's coefficients $(r)$ or Spearman's coefficients were reported, where task performance was controlled for in the analysis. Age distribution has been provided in Appendix $A$.

Attentional switch: Task Performance. Based on previous studies (Chong et al., 2017), task performance was computed as the overall percentage of trials in the Effort Experience phase where individuals had at least one hit and no more than two false alarms (i.e. $d^{\prime}>2$ ). Previous studies indicate chance performance to be near $0 \%$ (Moore et al., 2008). In our paradigm on each trial, there were 40 possible serial presentations on which participants could make a response. Based on this, to estimate chance performance, we simulated random behaviour in 


\section{EFFORT-RELATED DECISION-MAKING DURING CHILDHOOD}

79 agents based on the number of responses made by participants. For example, if a participant made 2 responses on a particular trial, the presentations on which these responses were made were randomly simulated. We compared these responses to presentations on which targets appeared. Using the number of responses made by our participants on each trial as a basis, we simulated a total of 2844 trials. Based on this, chance performance was estimated to be $10 \%$. Using a Repeated Measures ANOVA, we examined the differences in task performance between effort levels.

Demand Avoidance: Choice Behaviour. We measured the time taken to make a choice for either of the two options. Age effects were tested by the means of a 2-way repeated measures ANOVA with condition (i.e. low vs high effort) as a within-subjects factor and age as a betweensubjects factor. Paired t-tests were used for post-hoc analysis. Choice behaviour was measured by calculating the proportion of low effort trials chosen. To test if choice preference differed from chance, a Wilcoxon signed rank test was used as data was not normally distributed (Shapiro-Wilk normality test; $p<.001$ ).

Demand Avoidance: Preference Statement. We examined the proportion of individuals that stated a preference for low vs high effort task and if this differed from chance using a Wilcoxon signed rank test (Shapiro-Wilk normality test; $p<.001$ ).

Metacognition. Performance $\left(d^{\prime}\right)$ was calculated based on the hits (i.e. correct target detection) and false alarms (i.e. response when no target present), according to the following formula: $d^{\prime}=Z$ (hit rate) $-Z$ (false alarm rate). Based on this, a performance range was calculated and ratings of performance were recoded to this scale. This allowed us to calculate a discrepancy score between actual performance and rated performance (Fleming \& Lau, 2014), which in turn was calculated separately for low and high effort trials performed (i.e. four 
trials each). Signs were removed so that the discrepancy score could indicate metacognitive accuracy. A higher discrepancy score indicated poorer metacognitive accuracy.

Effort Experience. The NASA Task Load Index was used to measure perceived effort and mental demand of the task and scores were transformed to a scale of 1 to 10 . Using Repeated Measures ANOVA, we examined the differences in perceived effort and mental demand between the 6 effort levels with Greenhouse-Geisser corrections made. As a measure of individual differences in perceived effort and mental demand, a line was fit onto participants' responses for effort levels 1-6.

Effort Discounting. The indifference values for each effort level were determined and used to calculate a discounting function for which the area under the curve was computed for each participant (Myerson, Green, \& Warusawitharana, 2001). Larger values indicate greater degree of effort discounting (Dixon, Jacobs, \& Sanders, 2006; Shiels et al., 2006; Lempert, Porcelli, Delgado, \& Tricomi, 2012). Repeated Measures ANOVA was used to examine differences between effort levels and paired t-tests were used to examine differences between each subsequent effort level.

\section{Results}

We examine implicit and explicit forms of effort-related decision-making during childhood and how alongside age, effort-related decision-making during childhood is related to individual differences in perceived effort, task performance and metacognitive insight into performance.

\section{Effort Experience and Task Performance}




\section{EFFORT-RELATED DECISION-MAKING DURING CHILDHOOD}

Overall performance was $53.48 \%(S D=31.11)$, which significantly differed from chance $(t(78)$ $=12.42, p<.001)$. Performance was constant across number of attentional switches (Figure 2A) and there was interaction with age $(p>3)$. Perceived effort increased with the number of attentional switches $(F(4.21,185)=6.79, p<.001$; Figure $2 \mathrm{~B})$ and this did not interact further with age $(p>.6)$. A similar pattern was observed for mental demand $(F(4.21,185)=$ 8.10, $p<.001$; Figure $2 \mathrm{C})$, which also did not interact with age $(p>.3)$.

\section{Effort-related decisions}

Demand Avoidance: Choice Behaviour. When analysing reaction times in the demand avoidance task, we found a main effect of Condition $(F(1,77)=3.96, p=.05$; Figure 3B) as well as a significant 2-way interaction between Condition and $\operatorname{Age}(F(1,77)=12.60, p<$ .001$,$) . Whereas all children took longer to choose the high effort over the low effort option,$ this effect was particularly pronounced in younger children $(t(38)=-3.55, p<.001)$. Across the sample, low effort and high effort options were chosen with equal frequency (low effort choice $=47.2 \%$; see Figure $3 \mathrm{~A})$. This did not change with age $(r=.15, p=.187)$.

Demand Avoidance: Preference Statement. Across all children, there was no stated preference for either option (low effort preference $=46.8 \%$ ). This did however change with age $(r=-.24, p=.031$; Figure $3 C)$, whereby older children increasingly stated a preference for the low effort option. Visual inspection of the data suggests that a switch in preference occurs between 8-9 years. The relatively low numbers in each age group preclude further analysis.

Effort Discounting. There was a significant effect of attentional switches on subjective value $(F(3.92,274.68)=211.86 ; p<.001)$. This was most pronounced between attentional switch levels 1 and $2(t(74)=35.83 ; p<.001$; Figure 3D. Age was not significantly associated with effort discounting $(r=-.08 p=.509)$. 
Relationships between effort-related decision-making tasks. Choice behaviour and stated preference in the demand avoidance paradigm were significantly correlated $(r=-.54, p<.001)$, where implicit preference for low tasks was associated with stated preference of low effort tasks. Discounting was marginally correlated, albeit non-significant with both choice behaviour $(r=-.20, p=.094)$ and stated preference $(r=.23, p=.054)$ where a higher degree of discounting was marginally correlated with both choice preference and stated preference for low effort tasks.

Age and metacognition. There was a significant association between age and metacognitive abilities on low effort trials $(r=-.36, p=.002)$ and high effort trials $(r=-.23, p=.051)$.

Relationships with performance, metacognition and effort perception. Effort-related decisions and age were entered into a multivariate model alongside task performance, metacognition and effort perception. Choice behaviour in the demand avoidance task was associated with metacognitive accuracy on high effort tasks (Table 1), where better metacognitive accuracy on high effort trials was related to choosing high effort tasks more frequently than low effort tasks. Further, age remained significantly associated with stated preference for low effort. None of the candidate processes were found to be associated with effort discounting.

\section{Discussion}

This study used an attentional switch task to parametrically manipulate the experience of cognitive effort and address several outstanding questions in the development of effort-related decision-making in a large sample of children aged 5 to 11 years. We show that our 


\section{EFFORT-RELATED DECISION-MAKING DURING CHILDHOOD}

manipulation was successful in inducing concomitant parametric changes in both perceived effort and mental demand across the whole sample. This suggests that our modified version of an established attentional switch task is a suitable paradigm to parametrically induce subjective experience of effort in children. Analysis of effort-related decisions revealed that overall children demonstrated no implicit behavioural preference for low effort tasks, that older children stated a preference for low effort tasks and that children of all ages discounted effort. Finally, individual differences in metacognitive abilities accounted for implicit effort decisions.

We show that our fine-grained parametric manipulation of effort induced analogous changes in perceived effort and mental demand in children. This suggests that attentional switch tasks are a suitable manipulation of subjective effort in children. Such a parametric manipulation benefits effort discounting paradigms that have so far relied on coarser inductions of effort experience (Chevalier, 2018). Having shown that our task can successfully induce the subjective experience of effort in children, we set out to address how children use this to decide whether to engage in a cognitive task or not. Given that subtle differences in tasks are likely to affect both experience of effort and task enjoyment (Puca \& Schmalt, 1999), we sought to obtain convergent results by basing different decision-making paradigms on the same experience of effort unlike previous developmental research based on different paradigms (Chevalier, 2018; Niebaum et al., 2018).

We show that children reliably detect differences between high and low effort options in our demand avoidance. In spite of this, and unlike Niebaum et al. (2018), we do not find any age differences in choice behaviour. This may partly be due to the much lower number of trials compared to Niebaum et al. (2018), seeing that presumably demand avoidance emerges over time (Kool et al., 2010). Age differences did emerge when children were asked to state an explicit preference. In line with previous research, no age related differences were found in 


\section{EFFORT-RELATED DECISION-MAKING DURING CHILDHOOD}

explicit effort decisions (i.e. effort discounting; Chevalier, 2018). Interestingly, although all children discounted effort where they required more reward to perform high effort options, this did not increase parametrically with effort. This is curious as it suggests that despite incremental changes in effort perception and mental demand as a function of effort, unlike in adults (Chong et al., 2017) these do not translate parametrically into children's choices. Effort discounting requires complex computations of integrating the costs of simulated effort exertion and potential reward (Shenhav et al., 2013; 2017). It seems that even though effort is perceived parametrically, drawing on these representations to simulate future effort engagement is less sophisticated in children, especially compared to adults (Chong et al., 2017).

Taken together, the overall developmental pattern across the demand avoidance and effort discounting paradigms suggest that the explicitness of effort is crucial whether and at what point in development effort is taken into account in children's decision-making whether to engage or not. Making effort a salient feature of the decision-making process, as is done in discounting paradigms leads to children as young as 5 years to make choices indicative of a devaluation of effort. Subtler prompts to reflect on effort, such as asking to state a preference, leads to only older children using this feature to inform their decision-making, while in the same children the absence of any reference to effort-related features does not lead to demand avoidance. This suggests that developmental patterns of emergence and change in effortrelated decision-making are highly contingent on the salience of effortful features of task structure. Awareness of effort cues has been found to be crucial to effort avoidance (Dunn, Gaspar, \& Risko, 2019), while findings on the development of cognitive control have shown that younger children require cues to engage in proactive control, whereas older children can do so unprompted (Chevalier, Martis, Curran, \& Munakata, 2015). This strongly suggests that age-related changes in processing of effort-related cues drive both presently and previously observed developmental patterns in effort-related decision-making. Surprisingly, younger 


\section{EFFORT-RELATED DECISION-MAKING DURING CHILDHOOD}

children state a preference for high effort tasks when effort cues are present but sparse. It has been shown that younger children tend to more explorative in uncertain environments (Schultz, Wu, Ruggeri, \& Meder, 2019), where in the present case, a high effort task might afford a greater challenge and opportunity to learn (Kool \& Botvinick, 2014).

Our findings on the inter-relationships between different effort-related decision-making paradigms are somewhat mixed, with a robust association between implicit choice behaviour and a stated preference in the demand avoidance paradigm, and marginal associations between these two measures and effort discounting. It has previously been argued that effortrelated decision-making is a unitary construct subserved by a network of brain regions including the anterior cingulate cortex (Botvinick et al., 2009; McGuire \& Botvinick, 2010). Avoiding effort in implicit decisions requires online monitoring demands of several tasks and coordinating behaviour away from high effort tasks (Dunn et al., 2016; Kool et al., 2010; Niebaum et al., 2018), whereas effort discounting requires the offline computation of effort costs and weighing this against associated rewards (Shenhav et al., 2013; 2017). This supports the idea of both shared and distinct mechanisms for implicit and explicit forms of effort-related decision-making. We also found that individual differences in metacognitive abilities played a key role for implicit effort-related decision-making. Specifically, better metacognitive accuracy was associated with choosing high effort options. This was surprising as we expected children with better metacognitive abilities to be more sensitive to effort differences causing them to coordinate behaviour away from high effort tasks. One potential explanation is that children who are better able to judge their performance on high effort tasks choose high effort tasks as a strategy to reduce uncertainty (Lee \& Coricelli, 2020), choosing tasks where they are better aware of how they are performing in spite of the increased effort exertion required. 


\section{EFFORT-RELATED DECISION-MAKING DURING CHILDHOOD}

Our study has several limitations. Firstly, we did not measure enjoyment of effort. Therefore, we do not know how enjoyable children found our task which may have influenced how costly effort was perceived to be. Task enjoyment might be the most relevant contributor to decisionmaking especially in the absence of explicit effort cues. Further, individual trait differences in enjoyment of engaging with effort potentially confound our findings (Westbrook et al., 2013) with recent research showing neural networks modulate individual differences in effort seeking vs avoidance (Sayali \& Badre, 2019). Future developmental research should seek to account for both task-specific enjoyment and as well as individual differences in enjoyment derived from engaging with effort (Inzlict, Shenhav, \& Olivola, 2018). Further, the present demand avoidance was framed in prosocial terms (i.e. helping witches), introducing social incentives, which might be an additional source of unaccounted variance (Kray, Schmitt, Lorenz, \& Ferdinand, 2018). The task battery was designed such that the effort discounting paradigm was placed right at the end. This was done to avoid any influence of explicit knowledge of the effort manipulation on the implicit demand avoidance task. As a result, however, choices in the effort discounting could have been more susceptible to effects of fatigue or boredom (i.e. children could have been less willing to exert effort in the effort discounting paradigm as compared to earlier tasks due to fatigue or boredom. Future work that draws on a wider array of methods to operationalise effort would enable the counterbalancing required to rule out such fatigue or boredom effects that might emerge over time. Further, the extent to which current tasks (i.e. utilising attentional switches, rule switching and working memory; Chong et al., 2017; Niebaum et al., 2018; Chevalier 2018) are ecologically valid is questionable. Future work may focus on how different real-world contexts and factors interact to influence whether effort is perceived to be costly or as adding value (Inzlict et al., 2018). Finally, we are unable to rule out experimenter-induced effects. This is less of a concern in our implicit task as experimenters were blind to which task was associated with low or high effort. However, in our explicit effort discounting task both effort levels and reward levels were explicitly cued and therefore, experimenters may have influenced participants to pick options that were deemed more desirable. We tried to counter this by instructing and reassuring participants that they 


\section{EFFORT-RELATED DECISION-MAKING DURING CHILDHOOD}

should make selections that they want most and that there are no 'correct' or 'incorrect' selections. Even with this instruction in place, it is possible that participant choices were biased by the experimenter.

We studied the development of effort-related decision-making in 5-11-year-old children. We used a cognitive task to elicit granular experiences of effort. Based on their experience of this task, children then made decisions on several tasks on whether to expend cognitive effort. These tasks differed in the extent to which effort was made explicit. We show that the extent to which effort is highlighted is a crucial determinant for when children can use this information to guide their decision-making. This developmental pattern fits with literature on the effects of cues on proactive control development. Our account offers a synthesis for previously disparate developmental findings on effort-related decision-making. Future studies should include measures of task-enjoyment as a critical feature of willingness to engage with effortful tasks.

\section{References}

Bonnelle, V., Veromann, K. R., Heyes, S. B., Sterzo, E. L., Manohar, S., \& Husain, M. (2015). Characterization of reward and effort mechanisms in apathy. Journal of Physiology-Paris, 109, 16-26. https://doi.org/10.1016/j.jphysparis.2014.04.002

Botvinick, M. M., Huffstetler, S., \& McGuire, J. T. (2009). Effort discounting in human nucleus accumbens. Cognitive, Affective, \& Behavioral Neuroscience, 9, 16-27.

https://doi.org/10.3758/CABN.9.1.16

Carlson, S. M. (2005). Developmentally sensitive measures of executive function in preschool children. Developmental neuropsychology, 28, 595-616. 


\section{EFFORT-RELATED DECISION-MAKING DURING CHILDHOOD}

https://doi.org/10.1207/s15326942dn2802_3

Chevalier, N. (2018). Willing to think hard? The subjective value of cognitive effort in children. Child development, 89, 1283-1295. https://doi.org/10.1111/cdev.12805

Chevalier, N., \& Blaye, A. (2016). Metacognitive monitoring of executive control engagement during childhood. Child development, 87(4), 1264-1276. https://doi.org/10.1111/cdev.12537

Chevalier, N., Huber, K. L., Wiebe, S. A., \& Espy, K. A. (2013). Qualitative change in executive control during childhood and adulthood. Cognition, 128, 1-12.

https://doi.org/10.1016/j.cognition.2013.02.012

Chevalier, N., Martis, S. B., Curran, T., \& Munakata, Y. (2015). Metacognitive processes in executive control development: The case of reactive and proactive control. Journal of Cognitive Neuroscience, 27, 1125-1136. https://doi.org/10.1162/jocn_a_00782

Chong, T. T. J., Apps, M., Giehl, K., Sillence, A., Grima, L. L., \& Husain, M. (2017). Neurocomputational mechanisms underlying subjective valuation of effort costs. PLoS biology, 15, e1002598. https://doi.org/10.1371/journal.pbio.1002598

Cohen, J. (1988). Statistical power for the social sciences. Hillsdale, NJ: Laurence Erlbaum and Associates, 98-101.

Davidson, M. C., Amso, D., Anderson, L. C., \& Diamond, A. (2006). Development of cognitive control and executive functions from 4 to 13 years: evidence from manipulations of memory, inhibition, and task switching. Neuropsychologia, 44, 2037-2078.

https://doi.org/10.1016/j.neuropsychologia.2006.02.006

Dixon, M. R., Jacobs, E. A., \& Sanders, S. (2006). Contextual control of delay discounting by pathological gamblers. Journal of applied behavior analysis, 39 (4), 413-422. https://doi.org/10.1901/jaba.2006.173-05 


\section{EFFORT-RELATED DECISION-MAKING DURING CHILDHOOD}

Dreisbach, G., \& Fischer, R. (2015). Conflicts as aversive signals for control adaptation. Current Directions in Psychological Science, 24, 255-260.

https://doi.org/10.1177/0963721415569569

Dunn, T. L., Gaspar, C., \& Risko, E. F. (2019). Cue awareness in avoiding effortful control. Neuropsychologia, 123, 77-91.

https://doi.org/10.1016/j.neuropsychologia.2018.05.011

Dunn, T. L., Lutes, D. J., \& Risko, E. F. (2016). Metacognitive evaluation in the avoidance of demand. Journal of Experimental Psychology: Human Perception and Performance, 42, 1372. https://doi.org/10.1037/xhp0000236

Dunn, T. L., \& Risko, E. F. (2016). Toward a metacognitive account of cognitive offloading. Cognitive Science, 40, 1080-1127. https://doi.org/10.1111/cogs.12273

Fleming, S. M., \& Lau, H. C. (2014). How to measure metacognition. Frontiers in human neuroscience, 8, 443. https://doi.org/10.3389/fnhum.2014.00443

Foussias, G., Siddiqui, I., Fervaha, G., Mann, S., McDonald, K., Agid, O., ... \& Remington, G. (2015). Motivated to do well: an examination of the relationships between motivation, effort, and cognitive performance in schizophrenia. Schizophrenia Research, 166, 276282. https://doi.org/10.1016/j.schres.2015.05.019

Inzlicht, M., Shenhav, A., \& Olivola, C. Y. (2018). The Effort Paradox: Effort Is Both Costly and Valued. Trends in cognitive sciences, 22(4), 337-349.

https://doi.org/10.1016/j.tics.2018.01.007

Jara-Ettinger, J., Gweon, H., Schulz, L. E., \& Tenenbaum, J. B. (2016). The naïve utility calculus: Computational principles underlying commonsense psychology. Trends in cognitive sciences, 20(8), 589-604. https://doi.org/10.1016/j.tics.2016.05.011 


\section{EFFORT-RELATED DECISION-MAKING DURING CHILDHOOD}

Krebs, R. M., Boehler, C. N., \& Woldorff, M. G. (2010). The influence of reward associations on conflict processing in the Stroop task. Cognition, 117, 341-347.

https://doi.org/10.1016/j.cognition.2010.08.018

Kray, J., Schmitt, H., Lorenz, C., \& Ferdinand, N. K. (2018). The Influence of Different Kinds of Incentives on Decision-Making and Cognitive Control in Adolescent Development: A Review of Behavioral and Neuroscientific Studies. Frontiers in psychology, 9, 768. https://doi.org/10.3389/fpsyg.2018.00768

Kool, W., \& Botvinick, M. (2014). A labor/leisure tradeoff in cognitive control. Journal of experimental psychology. General, 143(1), 131-141. https://doi.org/10.1037/a0031048

Kool, W., McGuire, J. T., Rosen, Z. B., \& Botvinick, M. M. (2010). Decision making and the avoidance of cognitive demand. Journal of Experimental Psychology: General, 139, 665. https://doi.org/10.1037/a0020198

Kurzban, R., Duckworth, A., Kable, J. W., \& Myers, J. (2013). An opportunity cost model of subjective effort and task performance. Behavioral and brain sciences, 36, 661-679. https://doi.org/10.1017/S0140525X12003196

Kurzban, R. (2016). The sense of effort. Current Opinion in Psychology, 7, 67-70. https://doi.org/10.1016/j.copsyc.2015.08.003

Laurie-Rose, C., Curtindale, L. M., \& Frey, M. (2017). Measuring Sustained Attention and Perceived Workload: A Test With Children. Human factors, 59(1), 76-90.

https://doi.org/10.1177/0018720816684063

Lee, D., \& Coricelli, G. (2020). An Empirical Test of the Role of Value Certainty in Decision Making. Frontiers in psychology, 11, 574473. https://doi.org/10.3389/fpsyg.2020.574473 


\section{EFFORT-RELATED DECISION-MAKING DURING CHILDHOOD}

Lempert, K. M., Porcelli, A. J., Delgado, M. R., \& Tricomi, E. (2012). Individual differences in delay discounting under acute stress: the role of trait perceived stress. Frontiers in psychology, 3, 251. https://doi.org/10.3389/fpsyg.2012.00251

Leonard, J. A., Garcia, A., \& Schulz, L. E. (2019). Practice what you preach: How adults' actions, outcomes, and testimony affect preschoolers' persistence.

https://doi.org/10.1111/cdev.13305

Leonard, J. A., Lee, Y., \& Schulz, L. E. (2017). Infants make more attempts to achieve a goal when they see adults persist. Science (New York, N.Y.), 357(6357), 1290-1294. https://doi.org/10.1126/science.aan2317

Liu, S., Ullman, T. D., Tenenbaum, J. B., \& Spelke, E. S. (2017). Ten-month-old infants infer the value of goals from the costs of actions. Science, 358(6366), 1038-1041. https://doi.org/10.1126/science.aag2132

Lucca, K., Horton, R., \& Sommerville, J. A. (2020). Infants rationally decide when and how to deploy effort. Nature human behaviour, 4(4), 372-379. https://doi.org/10.1038/s41562-0190814-0

Lucca, K., \& Sommerville, J. A. (2018). The Little Engine That Can: Infants' Persistence Matters. Trends in cognitive sciences, 22(11), 965-968. https://doi.org/10.1016/j.tics.2018.07.012

Massar, S. A., Libedinsky, C., Weiyan, C., Huettel, S. A., \& Chee, M. W. (2015). Separate and overlapping brain areas encode subjective value during delay and effort discounting. Neuroimage, 120, 104-113. https://doi.org/10.1016/j.neuroimage.2015.06.080

McGuire, J. T., \& Botvinick, M. M. (2010). Prefrontal cortex, cognitive control, and the registration of decision costs. Proceedings of the National Academy of Sciences, 107, 79227926. https://doi.org/10.1073/pnas.0910662107 


\section{EFFORT-RELATED DECISION-MAKING DURING CHILDHOOD}

Moore, K. S., Wiemers, E. A., Kershner, A., Belville, K., Jasina, J., Ransome, A., \& Avanzato, J. (2018). Using Rapid Serial Visual Presentation to Measure Set-Specific Capture, a Consequence of Distraction While Multitasking. Journal of visualized experiments : JoVE, (138), 58053. https://doi.org/10.3791/58053

Muradoglu, M., \& Cimpian, A. (2020). Children's Intuitive Theories of Academic Performance. Child development, 91(4), e902-e918. https://doi.org/10.1111/cdev.13325

Myerson, J., Green, L., \& Warusawitharana, M. (2001). Area under the curve as a measure of discounting. Journal of the experimental analysis of behavior, 76(2), 235-243. https://doi.org/10.1901/jeab.2001.76-235

Nicholls, J. G. (1978). The development of the concepts of effort and ability, perception of academic attainment, and the understanding that difficult tasks require more ability. Child Development, 49(3), 800-814. https://doi.org/10.2307/1128250

Niebaum, J. C., Chevalier, N., Guild, R. M., \& Munakata, Y. (2018). Adaptive control and the avoidance of cognitive control demands across development. Neuropsychologia. 123, 152158. https://doi.org/10.1016/j.neuropsychologia.2018.04.029

Puca, R. M., \& Schmalt, H. D. (1999). Task enjoyment: A mediator between achievement motives and performance. Motivation and Emotion, 23(1), 15-29.

https://doi.org/10.1023/A:1021327300925

Robinson, M. M., \& Morsella, E. (2014). The subjective effort of everyday mental tasks: Attending, assessing, and choosing. Motivation and Emotion, 38, 832-843.

https://doi.org/10.1007/s11031-014-9441-2

Salamone, J. D., Yohn, S. E., Lopez-Cruz, L., San Miguel, N., \& Correa, M. (2016). Activational and effort-related aspects of motivation: neural mechanisms and implications for psychopathology. Brain, 139, 1325-1347. https://doi.org/10.1093/brain/aww050 


\section{EFFORT-RELATED DECISION-MAKING DURING CHILDHOOD}

Saunders, B., Lin, H., Milyavskaya, M., \& Inzlicht, M. (2017). The emotive nature of conflict monitoring in the medial prefrontal cortex. International Journal of Psychophysiology, 119, 3140. https://doi.org/10.1016/j.ijpsycho.2017.01.004

Sayali, C., \& Badre, D. (2019). Neural systems of cognitive demand avoidance. Neuropsychologia, 123, 41-54. https://doi.org/10.1016/j.neuropsychologia.2018.06.016

Schulz, E., Wu, C. M., Ruggeri, A., \& Meder, B. (2019). Searching for Rewards Like a Child Means Less Generalization and More Directed Exploration. Psychological Science, 30(11), 1561-1572. https://doi.org/10.1177/0956797619863663

Shenhav, A., Botvinick, M. M., \& Cohen, J. D. (2013). The expected value of control: an integrative theory of anterior cingulate cortex function. Neuron, 79, 217-240. https://doi.org/10.1016/j.neuron.2013.07.007

Shenhav, A., Cohen, J. D., \& Botvinick, M. M. (2016). Dorsal anterior cingulate cortex and the value of control. Nature neuroscience, 19, 1286. https://doi.org/10.1038/nn.4384

Shenhav, A., Musslick, S., Lieder, F., Kool, W., Griffiths, T. L., Cohen, J. D., \& Botvinick, M. M. (2017). Toward a rational and mechanistic account of mental effort. Annual review of neuroscience, 40, 99-124. https://doi.org/10.1146/annurev-neuro-072116-031526

Shiels, K., Hawk, L. W., Jr., Reynolds, B., Mazzullo, R. J., Rhodes, J. D., Pelham, W. E., Jr., Waxmonsky, J. G., \& Gangloff, B. P. (2009). Effects of methylphenidate on discounting of delayed rewards in attention deficit/hyperactivity disorder. Experimental and Clinical Psychopharmacology, 17(5), 291-301. https://doi.org/10.1037/a0017259

Shin, H., Bjorklund, D. F., \& Beck, E. F. (2007). The adaptive nature of children's overestimation in a strategic memory task. Cognitive Development, 22, 197-212. https://doi.org/10.1016/j.cogdev.2006.10.001

Umemoto, A., \& Holroyd, C. B. (2015). Task-specific effects of reward on task switching. Psychological research, 79, 698-707. https://doi.org/10.1007/s00426-014-0595-z 


\section{EFFORT-RELATED DECISION-MAKING DURING CHILDHOOD}

Westbrook, A., Kester, D., \& Braver, T. S. (2013). What is the subjective cost of cognitive effort? Load, trait, and aging effects revealed by economic preference. PloS one, 8, e68210. https://doi.org/10.1371/journal.pone.0068210

Westbrook, A., van den Bosch, R., Määttä, J. I., Hofmans, L., Papadopetraki, D., Cools, R., \& Frank, M. J. (2020). Dopamine promotes cognitive effort by biasing the benefits versus costs of cognitive work. Science, 367(6484), 1362-1366. https://doi.org.10.1126/science.aaz5891

Yantis, S., Schwarzbach, J., Serences, J. T., Carlson, R. L., Steinmetz, M. A., Pekar, J. J., \& Courtney, S. M. (2002). Transient neural activity in human parietal cortex during spatial attention shifts. Nature neuroscience, 5, 995. https://doi.org/10.1038/nn921 


\section{Tables and Figures}

Table 1. Summary of multivariate models examining the associations between effort decisions, age, task performance, metacognition, and effort perception.

Effort-Related Decision

$\beta$

(CI 95\%)

\begin{tabular}{|c|c|c|c|}
\hline \multirow[t]{7}{*}{ Choice Behaviour } & Age & $.11(-.03, .25)$ & .448 \\
\hline & Task Performance & $.06(-.08, .20)$ & .649 \\
\hline & \multicolumn{3}{|c|}{ Metacognition Scores } \\
\hline & Low Effort & $-.18(-.33,-.02)$ & .264 \\
\hline & High Effort & $.47(.30, .64)$ & .007 \\
\hline & Mental Demand & $.12(-.03, .27)$ & .426 \\
\hline & Perceived Effort & $.07(-.05, .19)$ & .576 \\
\hline & & $\begin{array}{l}\text { OR } \\
\text { (Cl 95\%) }\end{array}$ & p-value \\
\hline \multirow[t]{2}{*}{ Stated Preference } & Age & $0.62(0.42,0.92)$ & .017 \\
\hline & Task Performance & $1.00(0.98,1.02)$ & .806 \\
\hline
\end{tabular}

\section{Metacognition}

Scores

\begin{tabular}{|c|c|c|c|}
\hline & Low Effort & $0.89(0.65,1.24)$ & .500 \\
\hline & High Effort & $0.92(0.65,1.30)$ & .631 \\
\hline & Mental Demand & $3.10(0.67,14.34)$ & .146 \\
\hline & Perceived Effort & $1.21(0.46,3.19)$ & .706 \\
\hline & & $\begin{array}{l}\beta \\
\text { (CI 95\%) }\end{array}$ & p-value \\
\hline Effort Discounting & Age & $-.06(-.20, .08)$ & .663 \\
\hline & Task Performance & $-.23(-.37,-.09)$ & .104 \\
\hline & Metacognition Scores & & \\
\hline & Low Effort & $-.19(-.35,-.03)$ & .235 \\
\hline & High Effort & $.08(-.09, .25)$ & .631 \\
\hline & Mental Demand & $.01(-.13, .16)$ & .923 \\
\hline & Perceived Effort & $-.17(-.29,-.05)$ & .156 \\
\hline
\end{tabular}

Note: $\beta$ : beta coefficient value derived from linear regression; OR: $(5 \% \mathrm{Cl})$ - odds ratio derived from logistic regression; Cl 95\%: 95\% confidence interval 
(A)

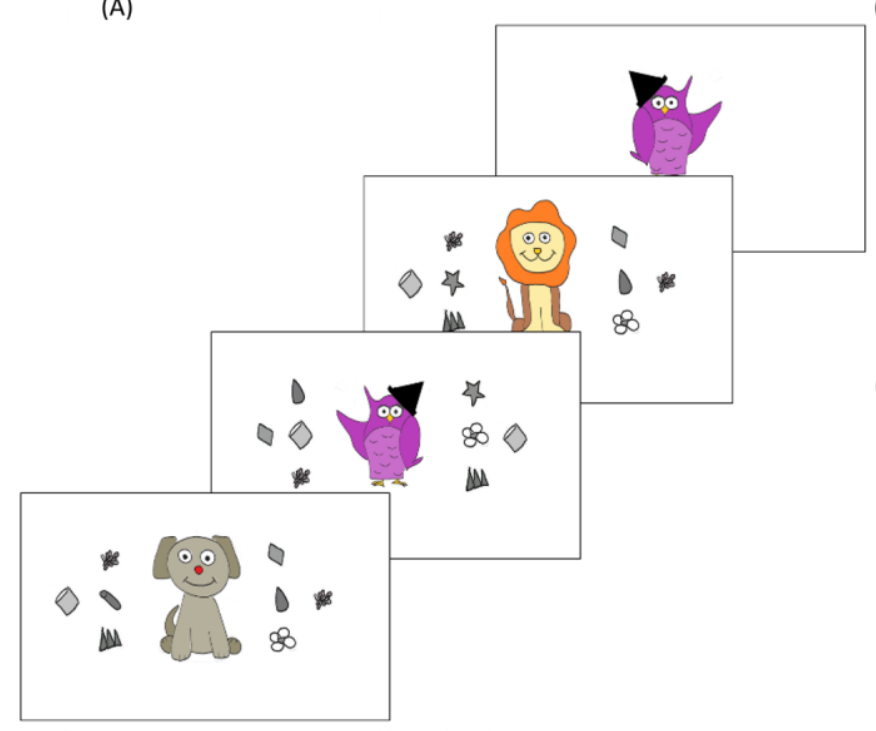

(B)

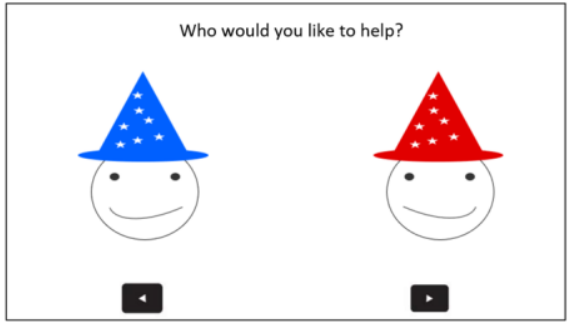

(C)

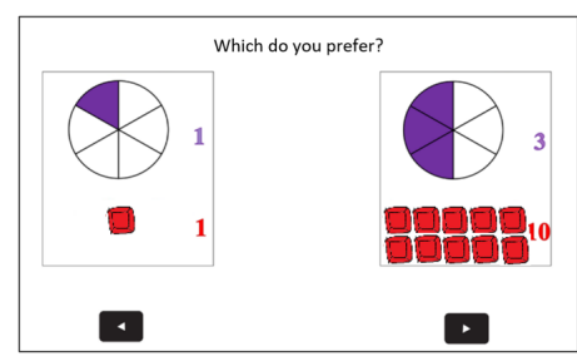

Figure 1. (A) Attentional switch task used to manipulate effort. After an initial direction cue, participants had to press the spacebar when a wand was presented and had to make an attentional switch when an owl was presented; (B) Demand Avoidance Paradigm where participants chose the witch they wanted to help followed by a low or high effort variant depending on their choice; (C) Effort Discounting Paradigm where participants chose between a baseline low effort/low reward option and a variable high effort/high reward option. 
(A)

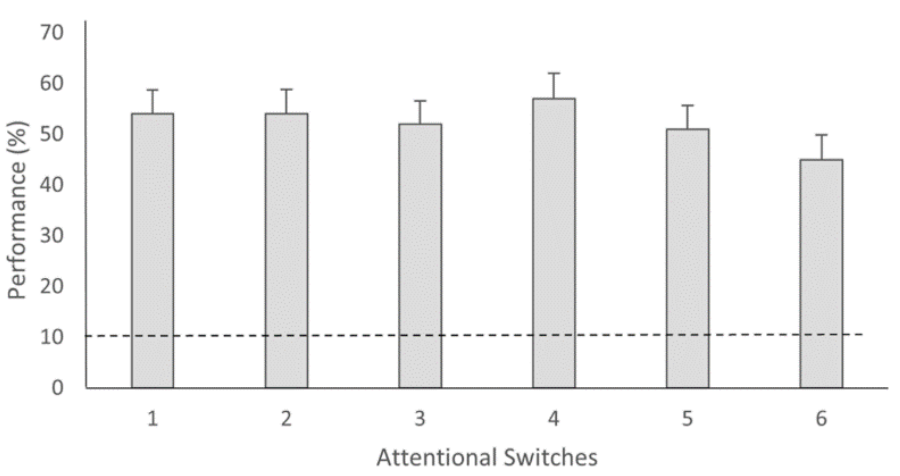

(B)

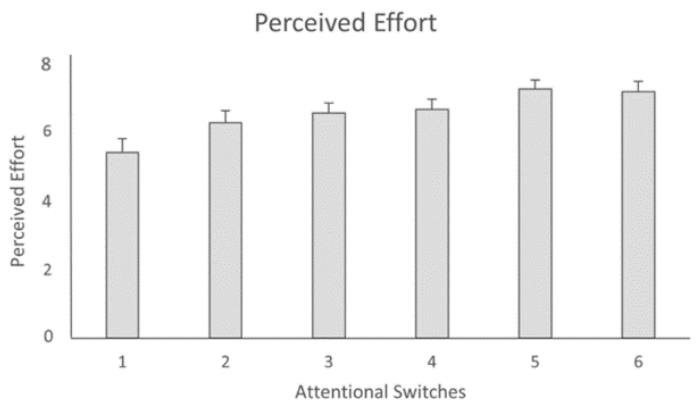

(C)

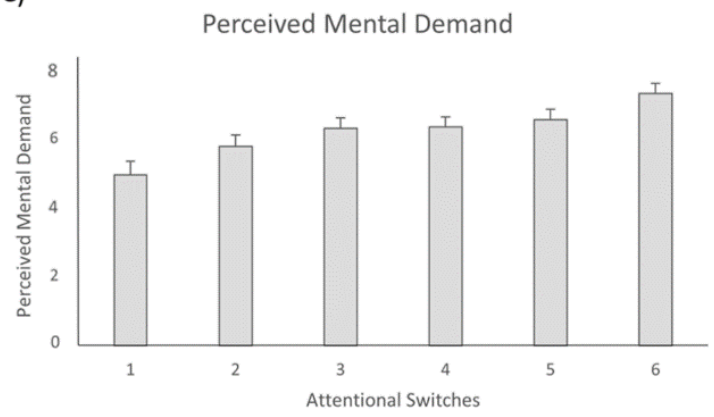

Figure 2. Numbers of attentional switches $(A)$ did not affect performance, but did impact $(B)$ perceived effort and $(C)$ mental demand. Dotted line in $(A)$ indicates chance performance.

(A)

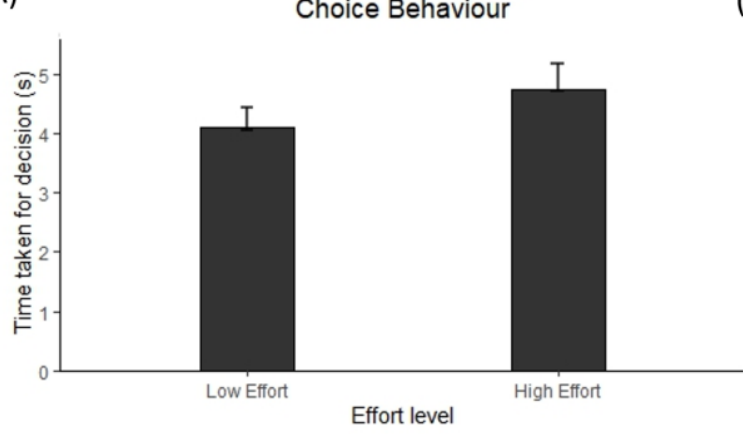

(C)

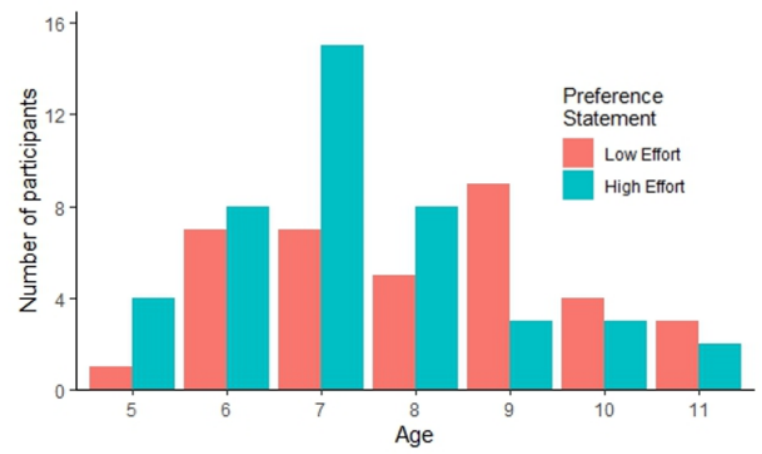

(B)

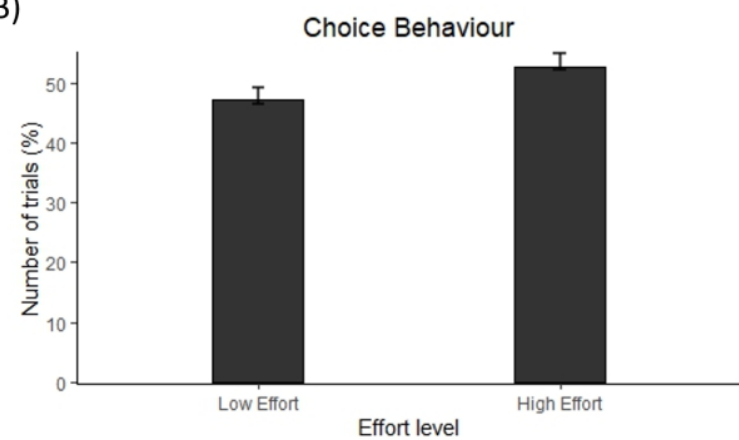

(D)

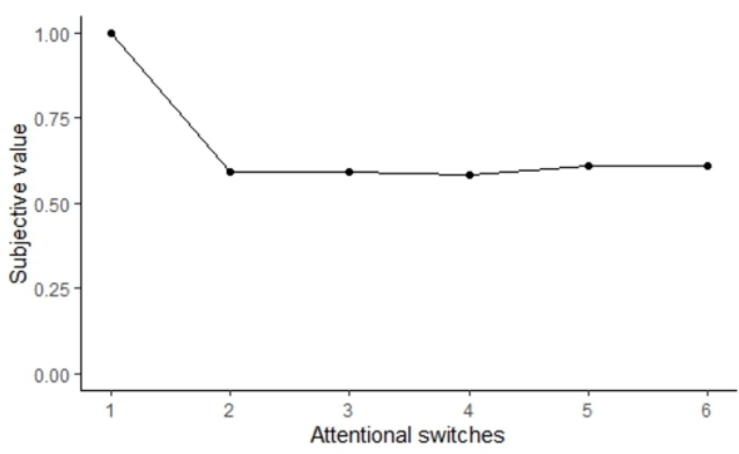

Figure 3. (A) There were no difference in proportion of effort options chosen. (B) High effort choices took longer than low effort choices. (C) Stated preference of low vs high effort task was associated with age; (D) Children of all ages significantly discount effort. 


\section{Appendix A}

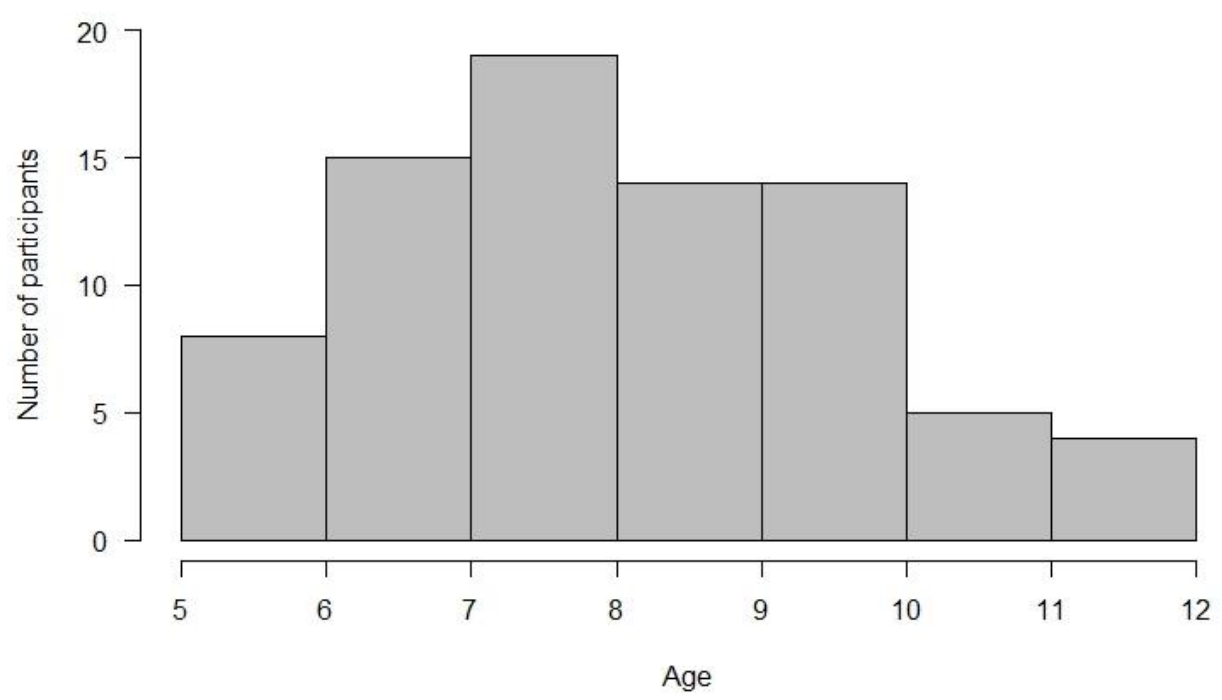

Figure A1. Age distribution of sample. 